\title{
CORRELATION BETWEEN DIFFERENT DEGREES OF OBESITY AND NON- SPECIFIC LOW BACK PAIN
}

Ghady Y. Mohammed*; Fatma S. Amin** and Yasser M. Aneis***

* Demonstrator of Physical Therapy for Basic science department, faculty of Physical Therapy, Deraya University

** Professor of Physical Therapy for Basic science department, Faculty of Physical Therapy, Cairo University;

*** Assistant Professor of Physical Therapy for Basic science department, Faculty of Physical Therapy, Cairo University.

Key Words: Obesity, Nonspecific low back pain, Spinal Mouse, Lumbar mobility.

\begin{abstract}
Background: Obesity is recognized as a major public health problem and it is associated with various musculoskeletal disorders, including impairment of the spine and osteoarthritis. Objective: to investigate the correlation between different degrees of obesity and non-specific low back pain as well as the mechanical factors that may affect this correlation. Methodology: Ninety obese females suffering from nonspecific low back pain participated in this study; their ages ranged from 20 to 45 years. Subjects were subdivided into three groups according to their BMI, thirty patients in each group. Group A, B and C represent grade I, II and III obesity respectively. Outcome measures were performed through spinal mouse that measure lumbar lordotic angle and spinal mobility and also through Visual analogue scale and Oswestery Disability index to detect pain severity and functional disability. Results: There was moderate positive significant correlation between BMI, VAS, ODI and lumbar mobility during extension, while there was moderate negative significant correlation between BMI and LLA as well as lumbar mobility during flexion. Conclusion: Different degrees of obesity correlate with non-specific low back pain as well as the mechanical factors that may affect this correlation.
\end{abstract}

\section{INTRODUCTION}

Obesity is nowadays a pandemic condition. Obese subjects are commonly characterized by musculoskeletal disorders and particularly by non-specific chronic low back pain (cLBP). However, the relationship between obesity and cLBP remains to date unsupported by an objective measurement of the mechanical behavior of the spine and its morphology in obese subjects. Such analysis may provide a deeper understanding of the relationships between function of the spine in flexion, extension and 
lateral bending and the onset of clinical symptoms (Vismara et al., 2010).

Also, there is lack of quantitative data regarding spinal mobility in obese subjects suffering from LBP (Shiri et al., 2010 a) and researchers identified wide variation among studies in the frequency and severity characterization of low back pain (Shiri et al., 2010 b).

Additionally, the analysis of the changes of spinal curvatures and movements is very important as it reflects the complex interaction between the anatomical and the muscular factors involved in this process (Singer et al., 1990). However, measurement of these curves with $x$-ray method for large sample, is not economical. In addition, there is a greater awareness of the hazards and dangers of radiation exposure associated with repeated radiographic evaluations. For these reasons, attempts are being made to develop skin-surface devices such as Spinal Mouse (SM) for use in examining the progression and treatment response of various spinal disorders (Emmanuelle et al., 2011) as SM showed high testretest reliability for evaluation of spinal curvatures and deformation in both sagittal and the frontal planes in patients with low back problems (Topalidou et al., 2014).

So, the aim of this research was

To investigate the correlation between different degrees of obesity and non-specific low back pain as well as the mechanical factors that may affect this correlation.

Design of the Study:

MATERIALS AND METHODS:

The study design was across-sectional study.

Subjects:

Ninety obese females with non-specific low back pain participated in this study. They were recruited from outpatient clinics of the Faculty of Physical Therapy, Deraya University; to be participants in this research. They were subdivided into three groups according to their BMI, thirty patients in each group. Group A with grade I obesity, Group B with grade II obesity; and Group C with grade III obesity. The Ethics Committee for scientific research of the Faculty of Physical Therapy, Cairo University was approved this research (No: P.T.REC/012/002479). All subjects signed a consent form prior to the beginning of assessment for ethical issues. Subjects recruited based on the following inclusion and exclusion criteria:

\section{Inclusive criteria:}

1) Age of participants range from $20-45$ years old (Koes et al., 2006).

1) Obese females with non-specific low back pain.

2) Waist circumference (abdominal obesity) was equal or more than 80 $\mathrm{cm}$ for women (Valery et al., 2009). 
3) BMI of participants was more than $30 \mathrm{~kg} / \mathrm{m}^{2}$, (also classified as Grade 1 ranging from 30 to 34.9 , Grade 2 ranging from 35 to 39.9, and Grade 3 more than 40) (WHO, 2016).

4) Subjects not receive any medication or diet management of obesity throughout the study.

\section{Exclusive criteria:}

Subjects were excluded from the study if they have previous spinal surgery, spinal cord injury or unstable neurological signs, congenital postural deformities, cauda equine symptoms related to the spine including changes in bowel and bladder control and females during pregnancy.

\section{Instrumentation:}

\section{(A)Evaluation instrumentation:}

\section{Standard Weight Scale (SWS) \& A stadiometer}

The standard medical weight scale was used to measure the weight in kilogram and a stadiometer to measure height in meter to calculate body mass index (BMI) of each subjects by dividing weight of subject per kilogram on her height square per meter (Ndubuisi et al., 2016).

\section{Tape Measurement}

It's a flexible form of ruler. It consists of plastic strip with linearmeasurement markings. It is a common tool of measurement (Aird, 1999).Tape measurement used to evaluate waist circumference which can be a predictable for central obesity where visceral adipose tissue is stored and hip circumferance is considered to be a separate measurement of body size that may represent other aspects of fat distribution (Kathrine et al., 2013).

\section{Spinal Mouse Idiag M360 pro (SM):}

Is a measuring device aided by an electronic computer which measure range of motion of the spine and evaluates the spinal angle and shape in the sagittal and frontal planes. The procedure is a non-invasive method. The Spinal Mouse's reliability was investigated and showed high test-retest reliability for evaluation of spinal curvatures, deformation, spinal mobility and the position of the body in both the sagittal and the frontal planes in patients with back or low back problems (Topalidou et al., 2014).

\section{Visual Analogue Scale (VAS):}

A visual analogue scale is $100 \mathrm{~mm}$ horizontal line with verbal descriptors expressing the severity of the pain sensation at each end. Patients label the point on the line that more represent the severity of their symptoms, since the following pain VAS cut points were recommended: no pain ( $0-4 \mathrm{~mm})$, mild pain $(5-44 \mathrm{~mm})$, moderate pain (45-74 $\mathrm{mm})$, and severe pain $(75-100 \mathrm{~mm})$ (Funke, 2004). The VAS is a 
widely used pain intensity assessment tool in rehab, proving to be accurate and valid (Crossley et al., 2004).

5. Oswestry low back pain disability questionnaire (ODI):

ODI is one of several scales developed for patients with low back pain to functionally assess daily activities. This scale was validated in different languages including Arabic version (Vogler et al., 2008).It consisted of 10 items; each item contains 6 levels of answers which can be scored from 0 to 5. Such items are: pain, personal care, lifting objects, walking, sitting, and standing, sleep disturbances induced by low back pain, sexual and social life and travel (Algarni et al., 2014).

\section{Evaluation Procedures:}

1. Body mass index (BMI):

The weights of each subject were obtained using standard weighting scale and heights were measured using astadiometer after removal of the shoes, with light clothing. This equation was used for calculating body mass index: BMI = weight per $\mathrm{kg} /$ height per $\mathrm{m} 2$ (WHO, 2011).

2.Waist Circumference Measurement (WC):

At the end of normal expiration, WC $(\mathrm{cm})$ was measured with the patient in standing position and the measuring tape positioned at the level of the lower floating rib (Dobbelsteyn et al., 2001).

\section{Hip Circumference Measurement (HC):}

$\mathrm{HC}$ was measured in centimeter with the patient in standing position by applying a plastic tape over light clothes at the widest width of the hip across the greater trochanters (WHO, 2011).

\section{Waist Hip Ratio (WHR):}

WHR is the WC to HC ratio that used for abdominal obesity evaluation. For females, central obesity is classified as WHR greater than 0.85 (WHO, 2011).Sometimes the WHR appears to be a better measure for central obesity than BMI or waist circumference, particularly among old age people (Srikanthan et al., 2009).

\section{Lumbar lordotic angle (LLA):}

Values for lumbar lordosis were obtained by using a spinal mouse (SM) that was shown to be accurate for sagittal plane evaluation of the spine (Mannion et al., 2004 and Miyazaki et al., 2010). Participants were instructed to remove their shirts and leave bras unhooked to allow access to paraspinal region. The spinous process of $\mathrm{C} 7$ and second sacral tubercle was marked with an eyeliner pencil. The spine scan was performed with bare foot or wearing socks. Participants were asked to look at a vertical column of numbers and gaze at the number at eye height until the scan was completed (Russell et al., 2012).

\section{Lumbar mobility:}

The SM which measures spinal inter-segmental angles in a safely manner also used to measure lumbar mobility in sagittal plane. The SM 
went along the spinal column from C7 to S3. The participants were instructed to take 3 consecutive positions; erect, maximal flexion and maximal spine extension. A measurement was performed in each position. For flexion, participants were told to touch toes with their fingertips , keeping knees straight and their feet about $30 \mathrm{~cm}$ apart. For extension, participants were instructed to extend their back as they can, with no assistance (Post et al., 2004).

\section{Pain severity:}

Participants were asked about their lower back pain that represented on a visual analog scale of pain. The answer was graded as 0 (without pain) to 10 (extreme pain possible); with mild pain being 0-3, moderate pain being 4-6, and severe pain being 7-10 (Alexandre et al., 2019).

\section{Functional disability:}

Participants were questioned about how back pain affects ability to manage everyday life. Total score of ODI is determined by sum all scores of applied items, dividing this score by total score (50) and multiplying it by (100) to get the score percentage (Dobbelsteyn et al., 2001). The score ranging from 0 percent (no disability) to 100 percent (full disability). The scale was interpreted according to: from 0 to 20 percent: minimal disability; from 20 to 40 percent moderate disability; from 40 to 60 percent severe disability; from 60 to 80 percent crippling low back pain and beyond percent the person is confined to bed (Fairbank et al.,1980).

\section{Statistical analysis:}

(1)Descriptive statistics in the form of Mean, standard deviation and median of $\{$ demographic and clinical data $\}$ and frequencies and percentage of categorical variables.

(2)ANOVA was carried out to compare LLA, mobility in flexion and extension between the three groups and followed by tukeys post hoc test to identify the significant difference between groups.

(3) Kruskal-Wallis test was conducted for comparison of the median values of ODI and VAS between the three groups and followed by Mann-Whitney $U$ test to identify the significant difference between groups.

(4)Pearson Correlation Coefficient was conducted to determine the correlation between BMI, LLA, mobility in flexion and extension, ODI and VAS.

(5)Simple linear regression was conducted to produce a prediction model for the values of LLA, mobility in flexion and extension, ODI and VAS from BMI. 
The significance level for all statistical tests was set at $\mathrm{p}<$ 0.05 and all statistical measurements were performed through the statistical package for social sciences (SPSS) version 25 for windows.

\section{Demographic data of Participants:}

\section{RESULTS}

\section{General characteristics of the subjects:}

No significant difference was found between groups $\mathrm{A}, \mathrm{B}$ and $\mathrm{C}$ in age $(\mathrm{F}=0.12, \mathrm{p}=0.88)$, hip circumference $(\mathrm{F}=2.13, \mathrm{p}=0.12)$ and WHR $(F=3.03, p=0.054)$. While there was a significant difference between groups in weight $(\mathrm{F}=83.41, \mathrm{p}=0.0001)$, height $(\mathrm{F}=4.3, \mathrm{p}=$ $0.01)$, BMI $(\mathrm{F}=300.38, \mathrm{p}=0.0001)$ and waist circumference $(\mathrm{F}=14.76$, $\mathrm{p}=0.0001)$ as in (Table1).

Table 1. Descriptive statistics of the participants:

\begin{tabular}{|c|c|c|c|c|c|c|c|}
\hline \multirow{2}{*}{ Variables } & \multirow{2}{*}{$\begin{array}{l}\begin{array}{l}\text { Total } \\
\text { sample } \\
(\mathrm{N}=90)\end{array} \\
\overline{\overline{\mathrm{X}} \pm \mathrm{SD}}\end{array}$} & \multirow{2}{*}{$\begin{array}{l}\text { Group } \\
\mathrm{A}(\mathbf{N}= \\
\mathbf{3 0}) \\
\mathrm{X} \\
\pm \mathrm{SD}\end{array}$} & \multirow{2}{*}{$\begin{array}{l}\text { Group } \\
\text { B }(\mathbf{N}= \\
30) \\
X \\
\pm \text { SD }\end{array}$} & \multirow{2}{*}{$\begin{array}{l}\text { Group } \\
\text { C }(\mathbf{N}= \\
\mathbf{3 0}) \\
X \\
\pm \text { SD }\end{array}$} & \multicolumn{3}{|c|}{$\begin{array}{l}\text { Comparison between group } \\
\mathrm{A}, \mathrm{B} \text { and } \mathrm{C}\end{array}$} \\
\hline & & & & & F-value & p- value & Sig \\
\hline Age (years) & $\begin{array}{l}31.48 \pm \\
8.42\end{array}$ & $\begin{array}{l}31.3 \pm \\
8.35\end{array}$ & $\begin{array}{l}31.06 \pm \\
9.05\end{array}$ & $\begin{array}{l}32.1 \pm \\
8.1\end{array}$ & 0.12 & 0.88 & NS \\
\hline Weight (kg) & $\begin{array}{l}90.73 \pm \\
12.6\end{array}$ & $\begin{array}{l}79.15 \pm \\
5.54\end{array}$ & $\begin{array}{l}89.16 \pm \\
6.38\end{array}$ & $\begin{array}{l}103.9 \\
\pm 9.78\end{array}$ & 83.41 & 0.0001 & $\mathbf{S}$ \\
\hline Height (cm) & $\begin{array}{l}156.53 \\
\pm 5.11 \\
\end{array}$ & $\begin{array}{l}158.33 \\
\pm 4.82 \\
\end{array}$ & $\begin{array}{l}156.66 \\
\pm 4.77 \\
\end{array}$ & $\begin{array}{l}154.6 \\
\pm 5.2 \\
\end{array}$ & 4.3 & 0.01 & $\mathbf{S}$ \\
\hline BMI $\left(\mathbf{k g} / \mathbf{m}^{2}\right)$ & $\begin{array}{l}37.1 \pm \\
5.24\end{array}$ & $\begin{array}{l}31.53 \pm \\
1.24\end{array}$ & $\begin{array}{l}36.36 \pm \\
1.48\end{array}$ & $\begin{array}{l}43.41 \\
\pm 2.63 \\
\end{array}$ & 300.38 & 0.0001 & $\mathbf{S}$ \\
\hline $\begin{array}{l}\text { Waist } \\
\text { circumference } \\
\text { (cm) }\end{array}$ & $\begin{array}{l}103.03 \\
\pm 11.56\end{array}$ & $\begin{array}{l}97.8 \pm \\
8.37\end{array}$ & $\begin{array}{l}100.2 \pm \\
9.23\end{array}$ & $\begin{array}{l}111.1 \\
\pm \\
12.28 \\
\end{array}$ & 14.76 & 0.0001 & $\mathbf{S}$ \\
\hline $\begin{array}{l}\text { Hip } \\
\text { circumference } \\
\text { (cm) }\end{array}$ & $\begin{array}{l}112.63 \\
\pm 11.42\end{array}$ & $\begin{array}{l}110.66 \\
\pm 10.07\end{array}$ & $\begin{array}{l}111.13 \\
\pm 9.55\end{array}$ & $\begin{array}{l}116.1 \\
\pm \\
13.74 \\
\end{array}$ & 2.13 & 0.12 & NS \\
\hline WHR & $\begin{array}{ll}0.91 & \pm \\
0.12 & \end{array}$ & $\begin{array}{l}0.88 \pm \\
0.09\end{array}$ & $\begin{array}{ll}0.9 & \pm \\
0.08 & \\
\end{array}$ & $\begin{array}{l}0.96 \pm \\
0.17\end{array}$ & 3.03 & 0.054 & NS \\
\hline
\end{tabular}

Non-significant difference in WHR between groups means the whole sample were homogenous regarding body fat distribution and obesity type. I.e. type of obesity whether android or gynoid so the type of obesity is not a confounding factor.

\section{Comparison between the three groups ( $\mathrm{A}, \mathrm{B}$ and $\mathrm{C})$ :}

The three groups $\mathrm{A}, \mathrm{B}$ and $\mathrm{C}$ differed significantly in the severity of non-specific low back pain, functional disability ,lumbar curve changes and mobility in flexion and extension $(\mathrm{p}=0.0001),(\mathrm{p}=$ $0.01),(\mathrm{p}=0.02),(\mathrm{p}=0.01)$ and $(\mathrm{p}=0.0001)$ respectively (Table 2$)$. 
Table 2. Severity of non-specific low back pain (VAS), Functional disability (ODI), lumbar curve abnormality and mobility abnormality in flexion and extension of the study group.

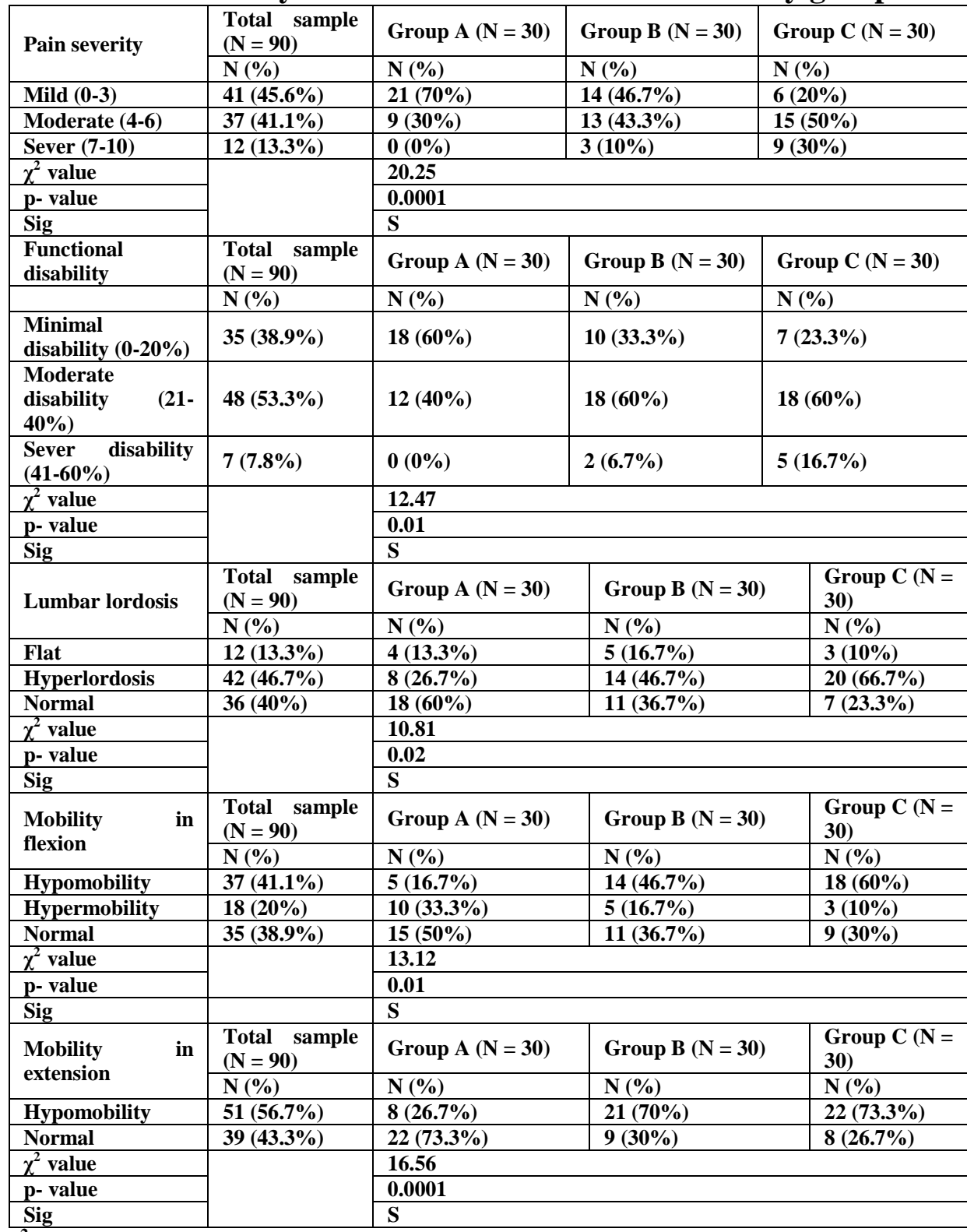

$\chi^{2}$ : Chi-squared value p value: Probability value S: Significant NS: Non Significant. There was a significant increase in the percent of mild level of pain, minimal disability and percent of normal curve in group A. while there was a significant increase in the percent of sever level of pain, 
moderate disability and the hyperlordosis in group $\mathrm{C}$ and also results revealed a significant increase in the percent of normal mobility during flexion and extension in group A while there was a significant increase in the hypo mobility in group B and C (Table 2).

Results regarding LLA show a significant increase in LLA of group $C$ relative to group $A(p=0.001)$ and group $B(p=0.02)$ also there was a significant increase in mobility during flexion of group $\mathrm{A}$ compared with that of group $\mathrm{C}(\mathrm{p}=0.0001)$ and group B compared with that of group $C(p=0.02)$ and also shows a significant increase in mobility during extension of group A relative to group $B(p=0.0001)$ and group $\mathrm{C}(\mathrm{p}=0.0001)$, but no significant difference in mobility during extension between group B and $\mathrm{C}(\mathrm{p}=0.52)$ as in (Table 3$)$.

Table 3.Differances between groups regarding $L L A$, mobility during flexion and extension, ODI and VAS.

\begin{tabular}{|c|c|c|c|c|c|}
\hline \multicolumn{3}{|c|}{ LLA (degrees) } & \multirow{3}{*}{ F-value } & \multirow{3}{*}{ p- value } & \multirow{3}{*}{ Sig } \\
\hline \multicolumn{3}{|c|}{$\overline{\mathrm{X}} \pm \mathrm{SD}$} & & & \\
\hline Group A & Group B & Group C & & & \\
\hline$-38.66 \pm 9.38$ & $-41.2 \pm 9$ & $-47.43 \pm 8.33$ & 7.67 & 0.001 & $\mathbf{S}$ \\
\hline \multicolumn{3}{|c|}{ Mobility during flexion } & \multirow{3}{*}{ F- value } & \multirow{3}{*}{ p- value } & \multirow{3}{*}{ Sig } \\
\hline \multicolumn{3}{|c|}{$\bar{X} \pm$ SD } & & & \\
\hline Group A & Group B & Group C & & & \\
\hline $64.33 \pm 15.27$ & $57.56 \pm 15.23$ & $47.6 \pm 12.48$ & 10.26 & 0.0001 & $\mathbf{S}$ \\
\hline \multicolumn{3}{|c|}{ Mobility during extension } & \multirow{3}{*}{ F- value } & \multirow{3}{*}{ p-value } & \multirow{3}{*}{ Sig } \\
\hline \multicolumn{3}{|c|}{$\bar{X}_{ \pm S D}$} & & & \\
\hline Group A & Group B & Group C & & & \\
\hline$-12 \pm 3.17$ & $-7.5 \pm 2.86$ & $-6.7 \pm 2.52$ & 29.84 & 0.0001 & $\mathbf{S}$ \\
\hline & I $(\%)$ & & \multirow{3}{*}{$\chi^{2}$} & \multirow{3}{*}{ p- value } & \multirow{3}{*}{ Sig } \\
\hline \multicolumn{3}{|c|}{ Median } & & & \\
\hline Group A & Group B & Group C & & & \\
\hline 18 & 26 & 27.5 & 16.09 & 0.0001 & $\mathbf{S}$ \\
\hline & $S(\%)$ & & \multirow{3}{*}{$\begin{array}{c}\chi^{2} \\
\text { value }\end{array}$} & \multirow{3}{*}{ p- value } & \multirow{3}{*}{ Sig } \\
\hline \multicolumn{3}{|c|}{ Median } & & & \\
\hline Group A & Group B & Group C & & & \\
\hline 3 & 4 & 6 & 17.7 & 0.0001 & $\mathbf{S}$ \\
\hline
\end{tabular}

$\chi^{2}$ : Chi-squared value p value: Probability value S: Significant NS: Non Significant

Results regarding ODI show a significant decrease in ODI of group A relative to group $B(p=0.003)$ and group $C(p=0.0001)$. Also results show regarding VAS a significant decrease in VAS of group A relative to group $\mathrm{C}(\mathrm{p}=0.0001)$ and group $\mathrm{B}(\mathrm{p}=0.008)($ Table 3$)$.

3. Correlation between BMI and VAS as well as other mechanical factors:

- There was moderate positive significant correlation between BMI and VAS $(r=0.41, p=0.0001)$ and between BMI and ODI $(r=0.42, p=$ $0.0001)$ (Table 4).

- There was moderate negative significant correlation between BMI and LLA $(\mathrm{r}=-0.38, \mathrm{p}=0.0001)($ Table4). 
- There was moderate negative significant correlation between BMI and mobility in flexion while moderate positive significant correlation between BMI and mobility in extension $(r=-0.43, p=$ $0.0001)$ and $(r=0.54, p=0.0001)$ respectively (Table 4).

Table.4: Correlation between BMI, VAS ,LLA,Lumbar mobility and ODI:

\begin{tabular}{|l|l|l|l|l|}
\hline & & r value & p value & Sig \\
\cline { 2 - 5 } BMI & VAS & $\mathbf{0 . 4 1}$ & $\mathbf{0 . 0 0 0 1}$ & S \\
\cline { 2 - 5 } & LLA & $-\mathbf{0 . 3 8}$ & $\mathbf{0 . 0 0 0 1}$ & S \\
\cline { 2 - 5 } & Mobility in flexion & $\mathbf{- 0 . 4 3}$ & $\mathbf{0 . 0 0 0 1}$ & S \\
\cline { 2 - 5 } & Mobility in extension & $\mathbf{0 . 5 4}$ & $\mathbf{0 . 0 0 0 1}$ & S \\
\cline { 2 - 5 } & ODI & $\mathbf{0 . 4 2}$ & $\mathbf{0 . 0 0 0 1}$ & S \\
\hline
\end{tabular}

r value: Pearson correlation coefficient $\quad$ p value: Probability value $\quad$ S: Significant

\section{Regression analysis with prediction model:}

BMI can significantly predict the LLA $(\mathrm{F}=14.88, \mathrm{p}=0.0001)$, mobility in flexion $(\mathrm{F}=20.93, \mathrm{p}=0.0001)$ and extension $(\mathrm{F}=37.06, \mathrm{p}=$ $0.0001)$, the ODI $(\mathrm{F}=18.64, \mathrm{p}=0.0001)$ and VAS $(\mathrm{F}=17.96, \mathrm{p}=$ $0.0001)$ so that for each extra degree BMI, there is change in these parameters (Table5).

Table.5 Regression analysis with prediction model of LLA, mobility in flexion and extension, $O D I$ and $V A S$ from BMI:

\begin{tabular}{|c|c|c|c|c|c|c|c|c|}
\hline \multirow{4}{*}{ LLA } & \multirow{2}{*}{$\mathbf{R}^{2}$} & & \multirow{2}{*}{ B } & \multirow{2}{*}{ t- value } & \multirow{2}{*}{$p$ value } & \multirow{2}{*}{ Sig } & \multicolumn{2}{|c|}{$95.0 \% \mathrm{CI}$} \\
\hline & & & & & & & Lower & Upper \\
\hline & \multirow{2}{*}{0.14} & Constant & -16.7 & -2.48 & 0.01 & $\mathbf{S}$ & -30.09 & -3.32 \\
\hline & & BMI & -0.69 & -3.85 & \begin{tabular}{|l|}
0.0001 \\
\end{tabular} & $\mathbf{S}$ & -1.05 & -0.33 \\
\hline \multirow{4}{*}{$\begin{array}{c}\text { Mobility } \\
\text { during } \\
\text { flexion }\end{array}$} & \multirow{2}{*}{$\mathbf{R}^{2}$} & & \multirow{2}{*}{ B } & \multirow{2}{*}{ t- value } & \multirow{2}{*}{$p$ value } & \multirow{2}{*}{ Sig } & \multicolumn{2}{|c|}{$95.0 \% \mathrm{CI}$} \\
\hline & & & & & & & Lower & Upper \\
\hline & \multirow{2}{*}{0.19} & Constant & 105.53 & 9.75 & \begin{tabular}{|l|}
0.0001 \\
\end{tabular} & $\mathbf{S}$ & 84.02 & 127.03 \\
\hline & & BMI & -1.32 & -4.57 & \begin{tabular}{|l|}
0.0001 \\
\end{tabular} & $\bar{S}$ & -1.89 & -0.74 \\
\hline \multirow{4}{*}{$\begin{array}{l}\text { Mobility } \\
\text { during } \\
\text { extension }\end{array}$} & \multirow{2}{*}{$\mathbf{R}^{2}$} & & \multirow{2}{*}{ B } & \multirow{2}{*}{ t- value } & \multirow{2}{*}{$p$ value } & \multirow{2}{*}{ Sig } & \multicolumn{2}{|c|}{$95.0 \%$ CI } \\
\hline & & & & & & & Lower & Upper \\
\hline & \multirow{2}{*}{0.29} & Constant & -22.89 & -9.74 & \begin{tabular}{|l|}
0.0001 \\
\end{tabular} & $\mathbf{S}$ & -27.55 & -18.22 \\
\hline & & BMI & 0.38 & 6.08 & \begin{tabular}{|l|}
0.0001 \\
\end{tabular} & $\mathbf{S}$ & 0.25 & -0.5 \\
\hline \multirow{4}{*}{ ODI } & \multirow{2}{*}{$\mathbf{R}^{2}$} & & \multirow{2}{*}{ B } & \multirow{2}{*}{ t- value } & \multirow{2}{*}{$p$ value } & \multirow{2}{*}{ Sig } & \multicolumn{2}{|c|}{$95.0 \% \mathrm{CI}$} \\
\hline & & & & & & & Lower & Upper \\
\hline & \multirow{2}{*}{0.17} & Constant & -3.46 & -0.52 & 0.6 & NS & -16.65 & 9.72 \\
\hline & & BMI & 0.76 & 4.31 & \begin{tabular}{|l|}
0.0001 \\
\end{tabular} & $\mathbf{S}$ & 0.41 & 1.11 \\
\hline \multirow{4}{*}{ VAS } & \multirow{2}{*}{$\mathbf{R}^{2}$} & & \multirow{2}{*}{ B } & t- value & n value & Sig & $95.0^{c}$ & CI \\
\hline & & & & L- value & p value & Sig & Lower & Upper \\
\hline & 017 & Constant & -2.53 & -1.62 & 0.1 & NS & -5.64 & 0.56 \\
\hline & 0.17 & BMI & 0.17 & 4.23 & \begin{tabular}{|l|}
0.0001 \\
\end{tabular} & $\mathbf{S}$ & 0.09 & 0.26 \\
\hline
\end{tabular}

B: Regression coefficient p value: Probability value

S: Significant NS: Non significant CI: Confidence interval 


\section{DISCUSSION:}

The present study investigated the correlation between different degrees of obesity and non-specific low back pain as well as the mechanical factors that may affect this correlation. Outcome measures were performed through spinal mouse that measure lumbar lordotic angle and spinal mobility and also through Visual analogue scale and Oswestery Disability index to detect pain severity and functional disability. Our results regarding LLA, lumbar mobility and functional disability showed a significant increase in the hyperlordosis and hypomobility and moderate disability in group B and C compared with group $\mathrm{A}$. While regarding pain severity, there was a significant increase in the percent of sever level in group C. Also results showed moderate positive significant correlation between BMI, VAS, ODI and lumbar mobility during extension, while there was moderate negative significant correlation between BMI and LLA as well as lumbar mobility during flexion. The results of our study explained by the results of (Shiri et al., 2010 b) that showed obesity could increase mechanical load by causing a higher compressive or shear forces on the lumbar spine structures during various activities. Additionally spinal mobility decreases with increasing body weight which may interfere with disc nutrition. (Heikki et al., 2015). Also, other previous study discussed the mechanism by which females have consistently higher of CLBP is partially known as related to exposure of the women to musculoskeletal loads due to pregnancy, child care and doubled workday and further more less muscle and bone mass as well as psychological characteristics (Ferreira et al., 2011; Altinel et al., 2008 ; Catherine et al., 2010; Rodrigo, 2013).

Also the current study founded that there was a significant difference between the three groups $\mathrm{A}, \mathrm{B}$ and $\mathrm{C}$ in severity of nonspecific low back pain, functional disability, lumbar curve changes and mobility in flexion and extension $(\mathrm{p}=0.0001)(\mathrm{p}=0.01)(\mathrm{p}=0.02)(\mathrm{p}=$ $0.01)(\mathrm{p}=0.0001)$ respectively.

Also our results state that BMI can predict severity of nonspecific low back pain, LLA, Lumbar mobility and functional disability. So that for each extra degree in BMI, there is change in these parameters.

The findings of this study regarding lumbar curvature were in the line with the findings of (Ndubuisi et al., 2016) who discussed the impact of obesity on lumbosacral angles as the lumbosacral angles were increased in persons with elevated body mass index and waist hip ratio. This can lead to biomechanical alteration of the lumbosacral spine that increases back pain. While (Joseph et al., 2002) compared range of motion (ROM) of lumbar spine and lumbar lordosis between patients with and without back pain with confounding variables as obesity and pain level were not controlled. As to minimize the effect of pain on the 
measurements, only patients with minimal or no pain at the time of testing were included in the study. The findings of this research revealed that no variations were found between the back pain and healthy groups in both lumbar ROM and lordosis. This may show that lumbar range of motion and lordosis of lumbar spine may not be the distinguishing variables between both groups.

The findings of this study agree with the findings of (Murrie et al., 2003) who showed that lumbar lordosis in individuals with a high body mass index (BMI) was significantly greater. Also agree with (Guo et al., 2008) who found that a BMI greater than $24 \mathrm{~kg} / \mathrm{m} 2$ could increase the angle of lumbar lordosis.

The findings of this study regarding lumbar lordotic angle and lumbar ROM is supported by (Vismara et al., 2010) who discussed the impact of obesity and low back pain on spinal mobility in women as obesity lead to reduce ROM of the spine due to reduced mobility in pelvic and thoracic level and also showed that obesity with chronic back pain is associated with an increase of lumbar lordosis.

Also the findings of this study are supported by (Lenková and Vasilišinová 2019) who investigated spinal mobility in women with sedentary job as obesity related to sedentary life style showing negative changes in the spine structure and mobility in both sagittal and frontal planes.

The findings of this study agreed with Bolgen-Cimen et al., 2007 who discussed the role of obesity in low back pain related disability as there was an increase of disability in patients with LBP when there was co morbid obesity. But Bolgen-Cimen et al., 2007 disagree with the present study as revealed that patients with LPB did not suffer from worse pain if they were obese but they experienced a more disabled life due to their weight as this study not demonstrated whether obesity can be considered in the etiology of LBP, but demonstrated only whether obesity is a factor responsible for disability in LBP patients.

The results of this study is confirmed by results of (Rodrigo et al., 2013) that revealed increase of chronic low back pain in a southern Brazil due to obesity as it causes overloading of the lumbosacral spine, which become susceptible to degenerative changes.

Results of the present study regarding functional level according to (ODI) agreed with (Alexandre et al., 2019) that discussed pain of the lower back and alignment of the spine in sagittal plane in obese individuals demonstrated low functional status in obese patients compared with their non-obese counterparts.

Results of this study regarding the lumbar curvature disagreed with the results of (James et al., 2006) who discussed the effects of BMI on lumbar spine in individuals with no existing low back pain showed 
that the impact of a degree of obesity on the standing lumbar curvature (SLC) is not considered to have a statistically significant effect.

Our results regarding lumbar curvature and pain intensity disagree with Hoseinifar, 2007 that stated, there no significant correlation between BMI and low back pain however, a significant correlation between lumbar lordosis and BMI suggesting that may be related to some difference in population age, tool of measurement and design of the study.

\section{CONCLUSION:}

Based on the results of the present study we can conclude that

Different degrees of obesity correlate with non-specific low back pain as well as the mechanical factors that may affect this correlation.

\section{RECOMMENDATION}

A similar study should be conducted on a large number of patients to provide a wide representation of the population. REFERENCES:

Aird, F. (1999): Mechanic's Guide to Precision Measuring Tools. Motorbooks International.

Alexandre Peixoto de Mello ; Glaucus Cajaty dos Santos Martins ; André Raposo Heringer ; Raphael Barbosa Gamallo ; Luiz Felippe dos Santos Martins Filho ; Antônio Vítor de Abreu ; Antonio Carlos Pires Carvalho and Maurício de Pinho Gama (2019): Back pain and sagittal spine alignment in obese patients eligible for bariatric surgery. European Spine Journal, 28(5): 967-975.

Algarni, A.S. ; S. Ghorbel ; J.G. Jones and M. Guermazi (2014): Validation of an Arabic version of the Oswestry index in Saudi Arabia. Annals of physical and rehabilitation medicine, 57(910): 653-663.

Altinel, L. ; K.C. Kose ; V. Ergan ; C. Isik ; Y. Aksoy ; A. Ozdemir and D. Toprak (2008): The prevalence of low back pain and risk factors among adult population in Opium region, Turkey." Acta Orthop Traumatol Turc, 42(5): 328-33.

Bolgen-Cimen, O ; N Arnc-Yncel ; M. Karabiber and C. Erdogan (2007): Role of obesity in low back pain related disability.West Indian Medical Journal, 56(3): 252.

Catherine, B. Johannes ; T. KimLe ; Xiaolei Zhou ; Joseph A. Johnston and Robert H. Dworkin (2010): The prevalence of 
chronic pain in United States adults: results of an Internet-based survey." The Journal of Pain, 11(11): 1230-1239.

Crossley, K.M. ; K.L. Bennell ; Cowan, S.M. and S. Green (2004): Analysis of outcome measures for persons with patellofemoral pain: which are reliable and valid?. Archives of physical medicine and rehabilitation, 85(5): 815-822.

Dobbelsteyn, C.J. ; M.R. Joffres ; D.R. MacLean and G. Flowerdew (2001): A comparative evaluation of waist circumference, waistto-hip ratio and body mass index as indicators of cardiovascular risk factors. The Canadian Heart Health Surveys. International journal of obesity, 25(5): 652-661.

Emmanuelle Chale'at-Valayer ; Jean-Marc Mac-Thiong ; Je'ro^me Paquet ; Eric Berthonnaud and Fabienne Siani (2011): Sagittal spino-pelvic alignment in chronic low back pain. European Spine Journal, 20(5): 634.

Fairbank, J.C. ; J. Couper ; J.B. Davies and J.P. O'brien (1980): The Oswestry low back pain disability questionnaire. Physiotherapy, 66 (8): 271-273.

Ferreira, G.D. ; M.C. Silva ; A.J. Rombaldi ; E.D. Wrege ; F.V. Siqueira and P.C. Hallal (2011):Prevalence of back pain and associated factors in adults in southern Brazil: a population-based study. Brazilian Journal of Physical Therapy, 15(1): 31-36.

Funke, F.(2004): Vergleich Visueller Analogskalen mit Kategorialskalen in Offline-und Online-Design (Doctoral dissertation, Magisterarbeit im Studiengang Soziologie am Institut für Soziologie des Fachbereichs Sozial-und Kulturwissenschaften der Justus-Liebig-Universität Gießen).

Guo, Jin-Ming and Guo-Quan Zhang (2008): Effect of BMI and WHR on lumbar lordosis and sacrum slant angle in middle and elderly women China journal of orthopaedics and traumatology, 21(1): 30-31.

Heikki Frilander ; Svetlana Solovieva ; Pertti Mutanen ; Harri Pihlajamäki ; Markku Heliövaara and Eira Viikari-Juntura (2015): Role of overweight and obesity in low back disorders among men: a longitudinal study with a life course approach. BMJ open, 5:1-8.

Hoseinifar, M. ; F. Ghiasi, and A. Akbari (2007): The relationship between lumbar and thoracic curves with body mass index and 
low back pain in students of Zahedan University of Medical Sciences. J Med science, 7(6): 984-90.

James, W. Youdas ; John H. Hollman and David A. Krause (2006): The effects of gender, age and Body mass index on standing lumbar curvature in persons without current low back pain, Physiotherapy Theory and practice, 22(5): 229-237.

Joseph, K.F. Ng ; Carolyn A. Richardson ; Vaughan Kippers and Mohamad Parnianpour (2002): Comparison of lumbar range of movement and lumbar lordosis in back pain patients and matched controls. Journal of Rehabilitation Medicine, 34(3): 109-113.

Kathrine, J. Vinknes ; Amany K. Elshorbagy ; Christian A. Drevon ; Clara G. Gjesdal ; Grethe S. Tell ; Ottar Nygård ; Stein E. Vollset and Helga Refsum (2013): Evaluation of the body adiposity index in a Caucasian population: the Hordaland health study. American journal of epidemiology, 177(6): 586-592.

Koes, B.W. ; M. Van Tulder and S. Thomas (2006): Diagnosis and treatment of low back pain. Bmj, 332(7555): 1430-1434.

Lenková, Rút and Veronika Vasilišinová (2019): Spinal Mobility in Women with Sedentary Job. Acta Facultatis Educationis Physicae Universitatis Comenianae, 59(2): 138-147.

Mannion, A.F. ; K. Knecht ; G. Balaban ; J. Dvorak and D. Grob (2004): A new skin-surface device for measuring the curvature and global and segmental ranges of motion of the spine: reliability of measurements and comparison with data reviewed from the literature. European Spine Journal, 13(2): 122-136.

Miyazaki, J. ; S. Murata ; C. Arakawa and S. Suzuki (2010): Reproducibility of spinal curve angle measurements using Spinal Mouse. Riagakuryoho Kagaku, 25(2): 223-6.

Murrie, V. L. ; A. K. Dixon ; W. Hollingworth ; H. Wilson and T. A. C. Doyle (2003): Lumbar lordosis: study of patients with and without low back pain." Clinical Anatomy: The Official Journal of the American Association of Clinical Anatomists and the British Association of Clinical Anatomists, 16(2): 144-147.

Ndubuisi, O.C. Onyemaechi ; Godson E. Anyanwu ; Emmanuel N. Obikili ; Okechukwu Onwuasoigwe and Okechukwu E. Nwankwo (2016): Impact of overweight and obesity on the musculoskeletal system using lumbosacral angles. Patient preference and adherence, 10: 291-296. 
Post, R. B. and V. J. M. Leferink (2004): Spinal mobility: sagittal range of motion measured with the Spinal Mouse, a new noninvasive device. Archives of Orthopaedic and Trauma Surgery, 124(3): 187-192.

Rodrigo, D. Meucci ; Anaclaudia G. Fassa ; Vera Mv Paniz ; Marcelo C. Silva and David H. Wegman (2013): Increase of chronic low back pain prevalence in a medium-sized city of southern Brazil. BMC musculoskeletal disorders,14(1): 155.

Russell, B.S. ; K.A. Muhlenkamp ; K.T. Hoiriis and C.M. DeSimone (2012): Measurement of lumbar lordosis in static standing posture with and without high-heeled shoes. Journal of Chiropractic Medicine, 11(3): 145-153.

Shiri, R. ; J. Karppinen ; P. Leino-Arjas ; S. Solovieva and E. Viikari-Juntura (2010): Incidence of nonspecific and radiating low back pain: follow up of 24-39-year-old adults of the Young Finns Study. Arthritis care \& research, 62(4): 455-459.

Shiri, R. ; J. Karppinen ; P. Leino-Arjas ; S. Solovieva and E. Viikari-Juntura (2010): The association between obesity and low back pain: a meta-analysis. American journal of epidemiology, 171(2): 135-154.

Singer, K. P. ; T. J. Jones, and P. D. Breidahl. (1990): A comparison of radiographic and computer-assisted measurements of thoracic and thoracolumbar sagittal curvature. Skeletal radiology, 19(1): 21-26.

Srikanthan, P. ; T.E. Seeman and A.S. Karlamangla (2009): Waisthip-ratio as a predictor of all-cause mortality in high-functioning older adults. Annals of epidemiology, 19(10): 724-731.

Topalidou, A. ; G. Tzagarakis ; X. Souvatzis ; G. Kontakis and P. Katonis (2014): Evaluation of the reliability of a new noninvasive method for assessing the functionality and mobility of the spine. Acta of Bioengineering and Biomechanics, 16(1): 118-124.

Valery, P.C. ; A. Moloney ; A. Cotterill ; M. Harris ; A.K. Sinha, and A.C. Green (2009): Prevalence of obesity and metabolic syndrome in Indigenous Australian youths. Obesity Reviews, 10(3): 255-261.

Vismara, L. ; F. Menegoni ; F. Zaina ; M. Galli ; S. Negrini and P. Capodaglio (2010): Effect of obesity and low back pain on 
spinal mobility:a cross sectional study in women. Journal of neuroengineering and rehabilitation, 7(1): 1-8.

Vogler, D. ; R. Paillex ; M. Norberg; P. de Goumoëns and J. Cabri (2008): Cross-cultural validation of the Oswestry disability index in French. In Annals of Rehabilitation and Physical Medicine, 51(5): 379-385. Elsevier Masson.

WHO, World Health Organization (2011): Waist circumference and waisthip ratio: report of a WHO expert consultation, Geneva, 8-11.

WHO, World Health Organization (2016): Obesity: Definition of obesity and overweight. Redefining Obesity and its treatment.

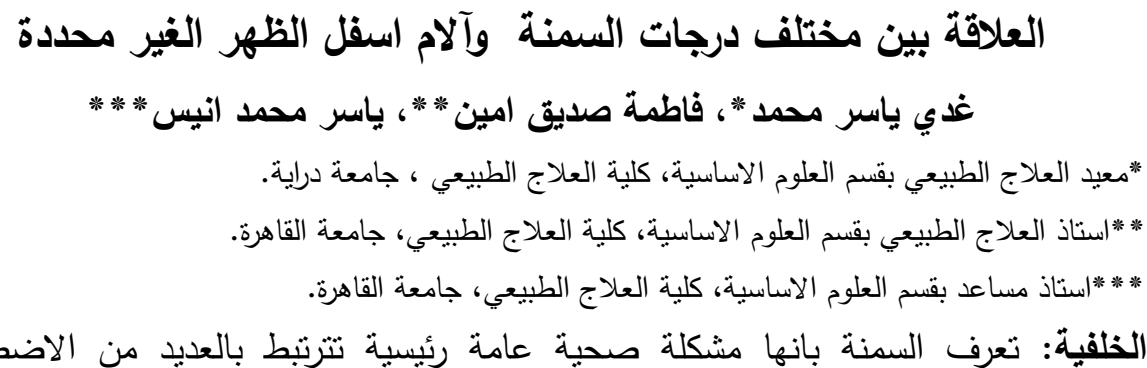

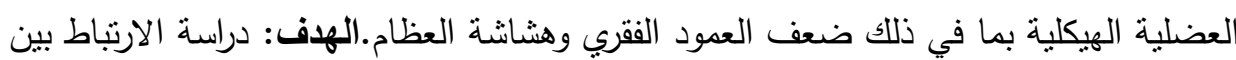
مختلف درجات السمنة وآلام اسفل الظهر الغير محددة وكذلك العوامل الميكانيكية التي قد تؤثنز

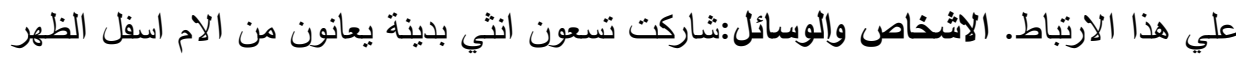

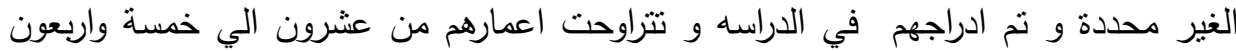

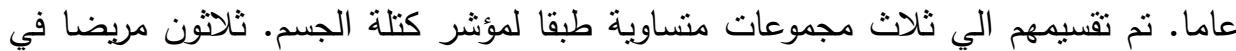

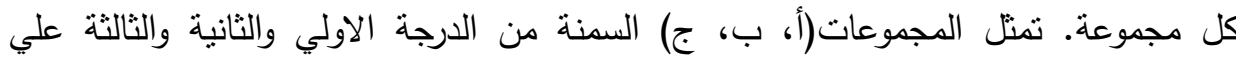

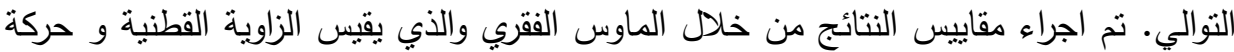

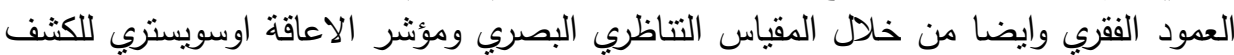

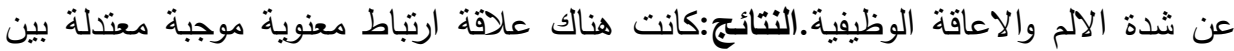
مؤشركتلة الجسم و المقياس التتاظري البصري ومؤشر الاعاقة اوسويستري والحركة القطنية اثثاء

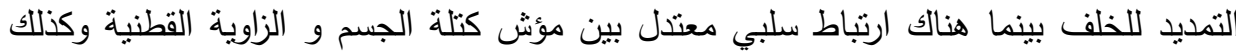

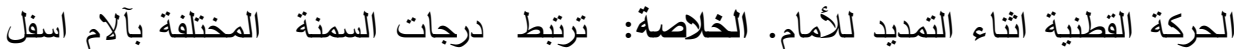

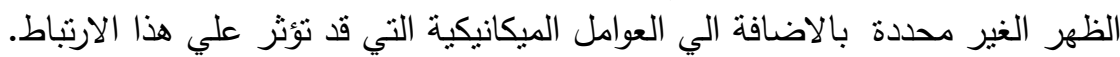
الكلمات الدالة: السمنة، آلام اسفل الظهر الغير محددة، الماوس الفقري و مدي الفي الحركة في الفقرات القطنية. - اته 